\title{
Anchoring in Ecosystemic Kinds
}

\author{
(Forthcoming in Synthese) \\ MatTHew H. Slater \\ Bucknell University \\ matthew.slater@gmail.com
}

The world contains many different types of ecosystems. This is something of a commonplace in biology and conservation science. But there has been little attention to the question of whether such ecosystem types enjoy a degree of objectivity — whether they might be natural kinds. I argue that traditional accounts of natural kinds that emphasize nomic or causal-mechanistic explanations dimensions of "kindhood" are ill-equipped to accommodate presumptive ecosystemic kinds. In particular, unlike many other kinds, ecosystemic kinds are "anchored" to the contingent character of species and higher taxa and their abiotic environments. Drawing on (Slater 2015a), I show how we can nevertheless make room for such contingent anchoring in an account of natural kinds of ecosystemic kinds.

\section{Introduction}

Are ecosystems real? Are they, in some sense, objective features of the world or are they artifacts of scientific convenience? These questions are multiply ambiguous. First, what is included under the heading 'ecosystem'? In his seminal text, Eugene Odum defines an ecosystem as "any entity or natural unit that includes living and nonliving parts interacting to produce a stable system in which the exchange of materials between the living and nonliving parts follows circular paths is an ecological system or ecosystem" $(1953,9)$. My usage in this context will be more varied, encompassing at once the very general bio-climatic categories sometimes called biomes (such as taiga and temperate forest) and evolutionary-ecological units revealed in the fossil record, as well as rather more local and specific ensembles of particular species or functional classes, sometimes called ecological communities or assemblages, and various cases in between.

Second, are we talking about the reality of token ecosystems or of ecosystem types? The former question has been taken up by philosophers and biologists since the inception of ecology. Its 
popularity likely stems from the famous debate between Clements (1916) and his immediate critics (Gleason 1917; Tansley 1935) concerning the analogy between an ecosystem and an organism. A number of separate questions are at stake here: Do ecosystems possess significant functional integration? Do they develop in predictable ways? Do they have more or less definite borders? Do they move and change as units? Are they individuals "whose parts bear causal relations to one another such that the object is highly structured and integrated" (Odenbaugh 2007, 630)? Alternatively, we might ask whether types of ecosystems preexist our efforts to classify them. Or put in the usual philosophical jargon, are there ecosystemic natural kinds? It is this second question that I wish to address here. Are there natural kinds of ecosystems? ${ }^{1}$

While my expansive approach to understanding the concept of an ecosystem permits me the opportunity to consider a variety of cases, albeit briefly, one might fairly suspect that it will make answering this second question difficult. Compare someone asking whether conspiracy theories are true. The right answer to this natural, if ill-conceived, question is that, yes, some conspiracy theories are indeed true, while others are not. Likewise for ecosystems; some appear deserving of treatment as natural kinds while perhaps others do not. ${ }^{2}$

The question I would like to address in this paper is how to satisfy this occasional (putative) demand. Doing so, I think, will point us in an interesting direction for thinking about the connection between natural kinds, causation, and contingency more generally. On many accounts, the concept of a natural kind is inextricably tied to ideas of either causation (or causal mechanism) or

\footnotetext{
${ }^{1}$ I will not have much to say about the first question for want of space and because it seems to me that the questions are perpendicular to each other, addressing very different theoretical desiderata; for more discussion, see $\$ 2$ below.

${ }^{2}$ I take a similar approach to the reality of biological species in chapter 6 of my (2013a). I have no particular view about whether we should see particular ecosystems as individuals (for useful discussion, see Odenbaugh 2007; Bryant 2012).
} 
natural law. These ideas are typically invoked to ward off contingency. ${ }^{3}$ I believe that a strict stance of this sort is mistaken. Some natural kinds — including ecosystemic kinds — are "anchored" in contingencies; a satisfactory account of natural kinds need not involve a causal or nomic dimension. In defending these claims, I will draw on other work in which I articulate such an account in some detail (2015a), but my focus will be on the general phenomenon of contingent anchoring of natural kinds.

The plan for the paper is as follows: In $\$ 2$, I briefly explore possible explanations for the neglect of the question about whether there are objective ecosystemic types; I'll argue that, skepticism aside, there is at least prima facie reason for thinking that there are and that an account of biological kinds should accommodate them. $\$ 3$ works to disentangle this issue from the question of whether ecology is a nomothetic or idiographic discipline. While it is possible for ecology not to admit of any (substantive) natural laws and still see ecosystems as parceled into types, these matters are not entirely disconnected. $\$ 4$ examines the tenability of the most popular approach to biological kinds — the Homeostatic Property Cluster (HPC) account — for accommodating ecosystem types. The final sections sketch my alternative approach and discuss the phenomenon of contingent anchoring.

\section{The Tenability of Realism About Ecosystemic Kinds}

To get started in earnest, let's briefly consider why ecologists and philosophers of biology have not paid more attention to ecosystems as a useful case study for a general theory of biological natural kinds. Three possible explanations come readily to mind: First, that it's just obvious that realism about ecosystemic kinds is true and can be easily vindicated by extant accounts of biological kinds

\footnotetext{
${ }^{3}$ More precisely: it is often hypothesized that requisite levels of non-contingency for natural kinds are only secured by appropriate causal relations or connections to natural laws.
} 
and so does not represent a very interesting test of those accounts. Second, that realism about ecosystemic kinds clearly should not be supported, unlike other positive cases of biological kinds (e.g., biochemical kinds or species), if such there be. Third, that ecosystemic kinds represent a kind of difficult, intermediate case that fits poorly with extant accounts of biological kinds. (A fourth explanation might be that philosophers of biology just haven't gotten around to looking at this domain in any depth.)

The first explanation can be dismissed quickly. Traditional realist approaches for accommodating scientists' classificatory activities include essentialism about natural kinds, now widely rejected in the philosophy of biology, and individualism (e.g., about species). But neither is very plausibly applied to ecosystems. Unlike species (perhaps), ecosystemic types are need not be spatiotemporally cohesive, even if token ecosystems are; such types are not credibly "hunks" of any tree of life. Essentialism may be somewhat plausible in a very limited range of cases but the same reasons that essentialism fails for species makes it problematic for most putative ecosystemic kinds as well.

The second explanation is more plausible. For some, skepticism about ecosystemic types presumably follows from skepticism about the objectivity of particular ecosystems. In Gleason’s famous, trenchant response to Clements' (1916) organicism, he argued that ecosystems (what he called "plant associations") are "merely a coincidence" $(1926,16)$. Somewhat confusingly, Gleason called his view Individualism (a label about which he later expressed some indifference — see his 1939, 93). What he had in mind was that each plant species — or indeed, each plant — acts independently of others; they behave "as individuals", seizing and using "the particular time-period 
during which the environment is in a condition suitable to it" $(1939,97)$. More recent naturalists have taken Gleason's basic line further:

Whittaker found, each species behaved totally independently.... What all this means is that there is no such thing, really, as a pine forest, or a mixed-hardwood forest or a tall-grass prairie or a tundra. These are human categories, not biological ones. They are simply names that we have applied in a rough attempt to impose intellectual order on the infinite diversity of landscapes that exist. (Budiansky 1995, 86, quoted in Odenbaugh 2007, 2635)

As Odenbaugh points out, Budiansky apparently conflates skepticism about token ecosystems with skepticism about ecosystem types; one may accept the reality of token ecosystems without accepting realism about ecosystem type $(2007,635) .{ }^{4}$ But Budiansky's basic strategy can be used to motivate anti-realism about ecosystemic types as well as tokens: If there is nothing that "holds together" the associations of different species in a putative ecosystemic type, then one might conclude they do not exist (apart from our penchant for recognizing and labeling them). This is the line of thought that I will argue is incorrect.

Thus, I favor the third (or fourth) explanation for ecosystems' neglect in the context of thinking about biological kinds. My starting point is the fact that many ecologists and conservation biologists of various stripes clearly talk as though there are objective ecosystemic types. Forestry, for example, has invested considerable resources in mapping and cataloguing various forest (and other vegetation) types across the globe; see below (Figure 1) for a typical example:

\footnotetext{
${ }^{4}$ It is not quite as clear that the reverse possibility holds. Can there be types of ecosystems without particular ecosystems, a forest with no trees? I happen to think that the answer to this question is 'yes', though I won't defend this line in any detail here; instead, I will simply presume that there are particular ecosystems (in whatever sense is workable) in asking whether there are also ecosystemic types.
} 


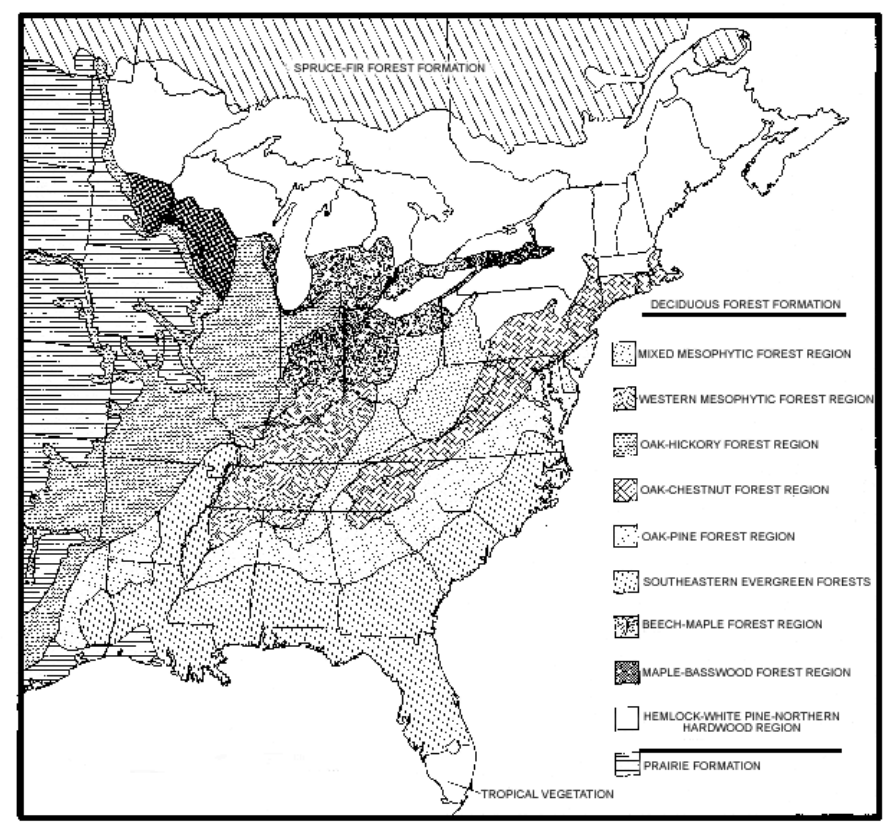

FIGURE $1^{5}$

As we'll see below shortly, the distribution of these high-level types often turns to be largely a

function of a small number of climatic variables. But it would be pointless to assemble diagrams like

Figure 2 unless terms like 'Pine-Oak Forest' had meaning outside of the Santa Catalina Mountains.

\footnotetext{
${ }^{5}$ http://www.srs.fs.usda.gov/sustain/report/histry/histry-29.htm\#P523_203600
} 


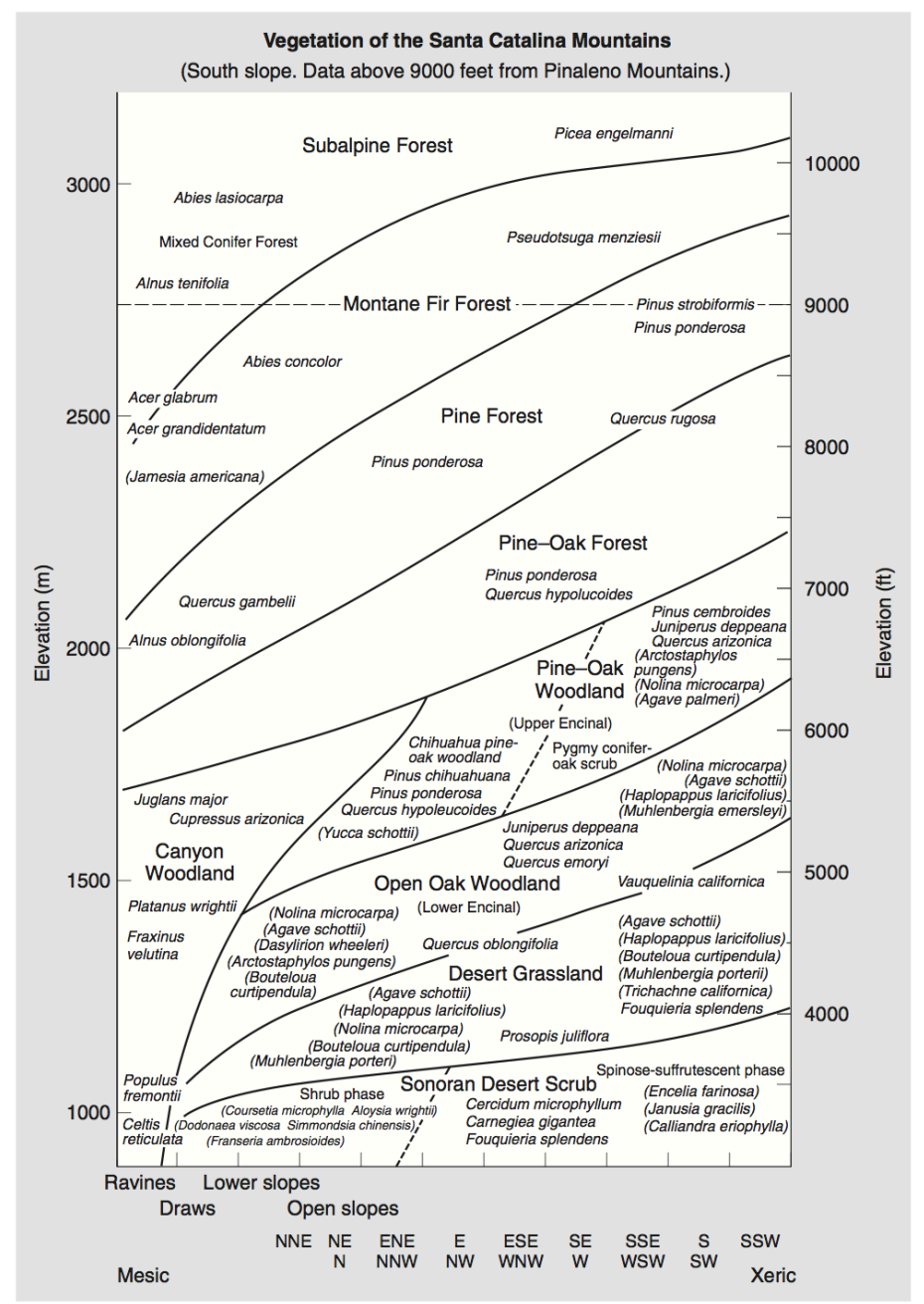

FIGURE 2: A gradient analysis of plant species at a site in Arizona; from Whittaker and Niering (1965) as reprinted in Morin (2011).

Indeed, ecosystem types play many of the same inferential and explanatory roles that more familiar examples of (purportedly) objective biological categories play. Palik and Engstrom note in motivating their chapter on forest management that "understanding successional pathways within ecosystem-types is important because management often depends on having informed predictions about future composition of forests" $(1999,66)$.

Prediction can be synchronic too, of course — and it is no less valuable. A popular general textbook on ecology, while in general advocating something close to Gleason's individualistic view, 
puts matters like this: "Results of direct gradient analysis, ordination and classification all indicate that a given location, by virtue mainly of its physical characteristics possesses a reasonably predictable association of species" (Begon et al. 2006, 463). This is precisely what enables the epistemic utility of local guides, such as the Terrestrial and Palustrine Plant Communities of Pennsylvania (edited by Zimmerman et al. 2012), the editors of which write in the introduction:

This classification is intended for a variety of agencies and organizations. Its potential applications include mapping, environmental impact assessment, development planning, site selection for long term monitoring, preserve design, and a variety of other activities related to the setting of priorities for conservation. It may also be useful in providing a common language to researchers and managers, as well as for educational purposes. $(\$ 1$, p. 6$)$

So we have an apparent tension. On the one hand, ecologists and other experts seem to treat ecosystemic types as important tools for understanding and interacting with the natural world. On the other hand, we have the (purported) observation of the contingency and relative causal independence of the species that comprise a given ecosystemic type (or token ecosystem) which suggests that ecosystemic types are mirages of classificatory prejudice, anchored to the conditions that prevail at a particular time and place.

Anti-realism about ecosystemic types can thus be opposed by responding to this second observation, arguing that the apparent causal independence and contingency of species associations is merely apparent. Perhaps the realist can identify a sense in which ecosystemic kinds may be understood as non-contingent associations secured by appropriate causal/nomic mechanisms. In the next two sections I consider and reject this strategy as untenable. Ultimately, I argue that the 
recognition of ecosystemic kinds is compatible with their contingent anchoring in a particular evolutionary or biogeographical milieu.

\section{Ecological Laws and Kinds}

Seminal philosophers of science such as Nagel and Hempel suggested a tight functional (though perhaps not definitional) connection between kinds and laws (Nagel 1961, 31; Hempel 1965, 139). Later philosophers suggested that we might see natural kinds as the categories figuring into laws (e.g., Kitcher 1984, 315-316); on Marc Lange's account (2000), this relation itself must be a matter of law: "to say that the electron is a natural kind of material particle is to say that there exist laws 'All electrons are...' of each of the $m$ sorts stipulated by such a meta-law" (221). Scientific Essentialists and powers enthusiasts typically reverse this dynamic, placing kinds and power-properties at the root of nomic phenomena (Ellis 2001; Mumford 2005).

These broadly nomic conceptions of natural kinds cohere nicely with the essentialist picture of kinds that emerged in the 1970s in Kripke's and Putnam's work. On Putnam's view, the real essence of a natural kind would be a (typically microstructural) property that "held together" the other properties by which we normally distinguish that kind - presumably with the help of relevant natural laws linking such "deep-lying mechanisms" to these nominal essences $(1975,139)$. But for those who take seriously the possibility of natural kinds of biological and social phenomena, there is a two-fold problem with the nomic-essentialist approach. First, it appears that essentialism is generally untenable in these domains (Sober 1980; Okasha 2002; cf. Devitt 2008); the extensions of candidate kinds do not all actually share some unique non-disjunctive property, to say nothing of their necessarily sharing such features. 
Even if essentialism is untenable, perhaps the recipe of kinds-as-nomic-categories might yet be made to work. Here we encounter the second difficulty. There has been considerable skepticism about the tenability of biological laws. As John Beatty argued in an influential paper, distinctively biological facts, being the products of indeterministic evolutionary processes, are "highly contingent" states of nature: "This means that there are no laws of biology" $(1995,46)$. The basic argument for this conclusion is simple and compelling. The truth of any biological generalization (that does not boil down to facts solely about chemistry, physics, or math) depends on facts about evolutionary processes that made it true. Such processes are deeply contingent. Even exceptionless biological facts — say, about the ubiquity of DNA or of certain metabolic processes — are mere accidents of evolution. Replay the "tape of life", and you'll get different outcomes (Gould 1989). Since no contingent generalization is a law, there are no biological laws. ${ }^{6}$

The argument is compelling, but not uncontestable. Perhaps some contingent generalizations might nevertheless be laws (Lange 1995, 2004; Sober 1997; Mitchell 2000, 2002; Woodward 2001; Haufe 2013). However, as Rosenberg points out, "The agreement that there are no...laws in biology is manifest in the valiant attempts of philosophers to redefine the concept of law so as to be able to dub descriptions of widespread historical patterns as laws, or necessary truths as laws" $(2001,737)$. This would be a fair point if Rosenberg had come to the table with a generally agreed-upon definition of natural law. But for defenders of biological kinds the blow connects rhetorically anyway; the prospect of defending one's account of biological kinds by first defending an account of physically contingent laws of nature is not particularly appealing.

\footnotetext{
${ }^{6}$ Variations on this basic theme can also be found in Dupré (1993) and Rosenberg (2001).
} 
Nevertheless, a longstanding debate within ecology has been on the degree to which its generalizations admit of law-like generality. Is ecology a "nomothetic" or "idiographic" discipline? There has been a bit of noise of late in favor of a limited return to the nomothetic outlook (Simberloff 1974; Mikkelson 2003; Cooper 2003; Ginzburg and Colyvan 2004; Lange 2005; Dodds 2009). Will any of this work, supposing that it is on the right track, lend support to the thesis of ecosystems as natural kinds?

Not directly; the proffered laws are of the wrong sort. Mikkelson, for example, focuses on his attention on the explanatory role of functional kinds in ecology — such as trophic specialist or primary consumer — and argues that in many cases, such kinds outperform historical kinds (such as particular taxa) in enabling accurate predictions. He summarizes the two main points of his argument like this:

(1) ecologists typically explain historical generalizations in terms of law-like generalizations, rather than vice versa; and that (2) this practice is justified, since structural and functional kinds, over which the latter range, typically correlate better with basic ecological patterns and processes than do historical kinds. $(2003,1397)$

But while Mikkelson allows that certain biomes will feature predictable patterns, the sorts of pattern generalizations he cites as laws do not centrally involve ecosystems as their predicates.

Cooper is happier to locate biome and habitat types as natural kinds within the "disciplinary structure" of ecology $(2003,121)$, but interestingly seems more reticent about the status of the relevant generalizations as natural laws, moved largely by evolutionary contingency considerations. He considers the idea of regarding laws as simply generalizations which possess a certain degree of "nomic force" but ultimately rejects this strategy and the existence of biological laws (181-3), 
providing the realist with little (that I can see) by way of potential grounding for the natural kinds he cites. This is not at all to say that they cannot be grounded. At the end of the day, perhaps his kinds are merely categories that help ecologists do their job more effectively (in the sense of Magnus 2012). Still, I suspect we can say more. Why are ecosystemic categories epistemically fruitful?

Ginsburg and Colyvan cite a number of striking macroecological allometries — "statistical regularities that hold between various biological and ecological quantities" $(2004,12)$ - as candidate laws. For example, the Kleiber allometry posits a 3/4 power proportionality between body size and metabolism that is constant within different functional groups (such as homeotherms, poikilotherms, and so on). But again, even if they are correct that such patterns ought to be treated as laws, they are not laws that impinge directly on ecosystems. Likewise for Lange (2005), who focuses his defense of ecological laws on the Area Law of island biogeography (MacArthur and Wilson 1967). ${ }^{7}$ Whether or not these theoretical generalizations may be counted as laws of ecology, I have not observed any support for laws concerning particular ecosystemic types.

Perhaps this shouldn't be surprising. One reason the Area Law and the Kleiber Allometry are laws of ecology concerns their relative independence from particular, highly-contingent evolutionary or biogeographical outcomes. Any purported law concerning a specific ecosystemic type, on the other hand, would presumably often reference specific taxa or physiognomic properties (e.g., broadleafed) that are tied to particular locales in evolutionary history. These are exactly the sorts of contingent products of evolution which Beatty's anti-nomic argument applies to most forcefully.

\footnotetext{
${ }^{7}$ Despite taking a fairly strict stance on the connection between kinds and laws (see above), Lange $(1995,2004)$ provides resources that I believe will be quite useful for making sense of ecosystemic kinds and natural kinds more generally. I'll come back to this point in $\$ 5$.
} 


\section{Ecosystems as HPC Kinds?}

Defenders of biological kinds in other domains have generally taken another tack. Rather than seeking out corresponding biological laws, they often subscribe to the somewhat less demanding requirement that natural kinds must track causal structure. One popular view that has justly gained the attention of philosophers of biology is Richard Boyd's Homeostatic Property Cluster (HPC) approach to natural kinds (lc. Boyd 1991, 1999). This view starts from the same empirical fact that motivated early essentialists: that many properties are regularly co-instantiated — regularly, but not always perfectly. Rather than posit an essence or law that explains such patterns, Boyd posited homeostatic causal mechanisms that would maintain such patterns, making the world inductively knowable:

Whatever philosophical importance (if any) there may be to the distinction between, on the one hand, causally sustained regularities..., and, on the other, LAWS (Ta!

Ta!), it is not reflected in the proper theory of natural kinds. (Boyd 1999, 152)

The advantage of the HPC account is thus two-fold: (1) it incorporates the idea of flexible, imperfect clustering of properties needed to accommodate our inferential and explanatory practices in domains (such as biology) that have proved challenging to the essentialist; and (2) it offers a way of understanding the "non-accidentality" of property clustering without having to invoke microstructural essences or strict natural laws. ${ }^{8}$

\footnotetext{
${ }^{8}$ For other articulations and elaborations of the HPC view, see Kornblith (1993), Griffiths (1997, 1999), Wilson (1999, 2005), Wilson et al. (2007), Slater (2015a). More epistemically-oriented accounts of natural kinds likewise opt to forge conceptual connections with causal rather than nomic concepts (Magnus 2012; Khalidi 2013). My attention here will be on Boyd's view as (loosely) representative of the general strategy; for brief discussion of Magnus and Khalidi, see Slater (2013b, 2015b).
} 
While we should regard this work as insightful and progressive, I believe that the insistence that we cleave our categories to causal structure of various sorts is still too restrictive. Part of my concern has to do with general features of the foundations of the HPC view — specifically involving the sufficiency of the relevant homeostatic mechanisms to ground the requisite stability of a given cluster of properties. Unfortunately, I do not have the space in this context to rehearse these arguments (see my 2015a). But fortunately these details need not concern us in the present context. Suppose one is generally happy with the HPC account's prowess at accommodating a wide array of categories in biology as natural kinds (as I think one might well be). Does it put us in a good position for handling ecosystemic kinds? To answer this question, we must address two main issues: first, do we see sufficient cross-instance patterns of properties characteristic of given ecosystems; and second, are these patterns explained by homeostatic mechanism?

To address the first question, let us focus our attention on plant associations (typical in this domain). We have already seen examples above of ecologists testifying to the "reasonably predictable" nature of such associations (Begon et al. 2006, 463). This presumption lies in the background of characterizations of particular associations. For example, Jean Fike characterizes a $d r y$ oak-mixed hardwood forest this way:

This type occurs on less acidic to somewhat calcareous, moderately dry soils. It is most often found on south and southwest-facing slopes. Common trees include Quercus alba (white oak), Betula lenta (sweet birch), Carya cordiformis (shellbark hickory), Celtis occidentalis (hackberry), Acer rubrum (red maple), A. saccharum (sugar maple), Q. montana (chestnut oak), Q. velutina (black oak), Q. rubra (northern red oak), Carya glabra (pignut hickory), Fraxinus americana (white ash), 
and Tilia americana (basswood). The shrub layer is perhaps more diagnostic. Characteristic shrubs include Cornus florida (flowering dogwood), Carpinus caroliniana (hornbeam), Corylus cornuta (beaked hazelnut), Amelanchier arborea (shadbush), Cercis canadensis (redbud), and Ostrya virginiana (hop-hornbeam). Ericaceous shrubs are uncommon, although Kalmia latifolia (mountain laurel) does occur on some sites. This type usually contains a somewhat richer herbaceous flora than the "Dry oak-heath" forest type (although restricted by moisture availability). Herbaceous species include Smilacina racemosa (false Solomon's-seal), Uvularia sessilifolia (wild-oats), Polygonatum biflorum (Solomon's-seal), Asplenium platyneuron (ebony spleenwort), Desmodium spp. (tick-trefoil), Hieracium venosum (rattlesnake weed), Aralia nudicaulis (wild sarsaparilla), Carex pensylvanica (a sedge), Carex communis (a sedge), and Lysimachia quadrifolia (whorled loosestrife). (Zimmerman et al. 2012)

Such characterizations can also take book-length form. Authors in Boreal Peatland Ecosystems (edited by Wieder and Vitt 2006) fill in the details of hydrology, climate, mineralogy, flora, and fauna falling under this broad characterization:

Peatland ecosystems, in the simplest definition, are terrestrial environments where over the long term, on an areal basis, net primary production exceeds organic matter decomposition, leading to the substantial accumulation of a deposit rich in incompletely decomposed organic matter, or peat. Under this very broad definition, peatland ecosystems can be found in arctic, boreal, temperate, or tropical climates. 
Not too surprisingly, a lot follows from these simple characteristics — not perfectly, mind you. There's plenty of scope for variation due to particularities of geography and climate. In his chapter on the functional characteristics of peatlands, Vitt notes that

Although ombrotrophic bogs are characteristically uniform throughout the boreal zone, several key geographical differences do occur. In boreal North America, Picea mariana dominates the tree layer; thus, all continental boreal bogs have a dense canopy beneath which Ledum groenlandicum normally dominates. As continentality decreases, Picea mariana decreases in cover until North American oceanic bogs become treeless, or have scattered individuals of Thuja plicata on the west coast (Vitt et al. 1990). In contrast, in eastern Asia, species of Larix (e.g., L. gmelinii and $L$. sibirica) dominate in bogs and fens, while in boreal Europe and western Asia, bogs are treeless or have only scattered individuals of Pinus sylvestris, with tree cover increasing with continentality. (15)

But such variations can either be handled smoothly by cluster approaches or (depending on one's investigative aims) the kinds can be refined via splitting.

Let's suppose that we are satisfied that at least some ecosystems can be characterized by the more or less reliable possession of a number of properties (including both biotic and abiotic factors). What about the second question above: Can we see these clusters of properties as being maintained and defined by causal homeostatic mechanisms? Early on, Boyd emphasized the importance of causal homeostatic mechanisms for grounding the reality of kinds. He writes that that kinds "cut the world at its joints" in the sense that "successful induction and explanation always require that we accommodate our categories to the causal structure of the world" (Boyd 1991, 139). Likewise, 
Craver and Darden claim that "biology has become a search for mechanisms" $(2013,6)$. For example, in discussing estuary mechanisms, they write

This eutrophication process can lead to a situation in which the oxygen levels in the estuary are chronically low (hypoxia). The runoff changes the nutrient balance of the estuary to encourage algae growth. Ever larger algae blooms choke out subsurface water plants by blocking both sunlight and nutrient flow, depriving the water of one main oxygen source. Then, after the nutrient overload ends and input levels return to normal, the algae population explosion ends and massive die-offs occur.

Decomposers then begin their work, and the sheer quantity of dead biomass being decomposed results in a rapid and substantial plummeting of dissolved oxygen. Damage done from this mechanism malfunction leads to expansive dead zones where little to no life can exist. Fish and shellfish kills erupt, which encourages further decomposer oxygen use. Under these circumstances, invasive species thrive, biodiversity decreases, and colonies of toxic bacteria, such as botulism, grow abundantly. This makes the waters even more dangerous for humans and other animals to drink. What was once a thriving estuary ecosystem can quickly become a watery wasteland. In the Chesapeake, expanses of the watershed are, it is believed, now damaged beyond self-regulated repair. By understanding the mechanisms of eutrophication, scientists and policy advisers are in a position to generate possible means of dealing with the problem of dead zones. $(2013,187-188)$

Descriptions of ecosystemic processes like this are common not only in explaining processes of decline, but in patterns of stasis. One finds all manner of mechanistic descriptions of various sorts 
going back to early days of the concept (see Golley 1993, ch. 2-4 for a survey). For example, socalled "assembly rules" for ecosystems (sensu Cody and Diamond 1975) fit the mechanistic profile well. In a recent review essay on contemporary thinking of these rules, Belyea and Lancaster describe them as being made true by underlying mechanisms and leading to various patterns:

[Assembly rules are] general principles arising from mechanisms operating within the community and to which the assembly of a community conforms. For example, the mechanism of consumer-resource dynamics... may underlie the rule that the proportion of available resources consumed increases as species invade (Diamond 1975). One pattern resulting from this rule is that invading species are likely to be drawn from different functional groups until each group is represented, before the pattern repeats.... (1999, 403 emphasis in original)

So far, so good. We have a general phenomenon — the stable co-instantiation of clusters of properties characteristic of certain categories - that we can explain by reference to causal homeostatic mechanisms. Such mechanisms thus take over the explanatory role of essences in providing the non-contingent grounding for this stability while at the same time accommodating the heterogenous, "messy" variations we normally see in biology.

But the analogy between causal homeostatic mechanisms and real essences is problematic in two different ways. First, essences serve to individuate kinds by defining what they are. What it is to be, say, gold or water is determined (according to the essentialist) by the real essences of these kinds their atomic and molecular structures, respectively. In his detailed discussions of the HPC approach, Paul Griffiths posits a similar individuative constraint: "Phenomena with the same explanation should be placed together and phenomena with different explanations drawn apart" $(1997,171)$. 
Categories that are not held together with causal mechanisms, on the other hand, should be rejected (ibid.). But this leads to a difficulty in maintaining an objective partitioning of kinds (see Craver 2009); in domains like ecology, it would lead to what many would regard as a radical over-splitting of kinds. Gleason gestured at this fact in his critique of Clementsian realism:

It must be remembered that we admit the essential uniformity of vegetation within a single community, and the frequent striking uniformity between adjacent communities. But the fact that these small cumulative differences do exist is basically important in the consideration of the general concept of the plant-association. They indicate that each community, and for that matter each fraction of one, is the product of its own independent causative factors, that each community in what we now choose to call an association-type is independent of every other one, except as a possible source of immigrating species. With no genetic connection, with no dynamic connection, with only superficial or accidental similarity, how can we logically class such a series of communities into a definite association-type? Truly the plant community is an individualistic phenomenon. $(1939,107)$

Gleason's comments are of course primarily concerned with token ecosystems, but the considerations he cites are relevant to the contention over kinds: there are, it seems, lots of ways in which the stability of a cluster of properties characteristic of an ecosystem can be held together. In Vitt's chapter on peatlands, he mentions four typical processes by which peatlands originate (10); the slight variations mentioned before between geographically-anchored peatland ecosystems can cascade in different directions and in different ways and yet, from a functional/physiognomic perspective, the overall appearance of the association remains relatively constant. Different mechanisms can give 
rise to and stabilize the same clusters of properties. Likewise, different mechanisms may be involved in the stable recurrence of distinct ecosystemic associations.

An HPCer might respond by backing off from Griffiths' requirement that mechanisms play a role in individuating ecosystemic kinds (or kinds in general), notably sacrificing one aspect of the analogy between essences and homeostatic mechanisms. Ideally, they would supply an alternative sense in which we are to accommodate our epistemic practices to the causal structure of the world; perhaps the only requirement should be that HPC natural kinds are maintained by some causal mechanisms. I leave this matter aside here to pursue the second disanalogy that is more important for our present concerns.

For essentialist kinds, the essence is supposed to explain why the characteristic nominal properties of a kind are reliably, non-accidentally found together. For HPC kinds, mechanisms are supposed to play the same sort of metaphysical/explanatory role. But whereas essences explain why these particular properties are found together, the mechanisms involved in the stable recurrence of properties associated with ecosystems (the association of species and environments, and so on) often explain only the stable maintenance of a cluster of properties without explaining why those properties are the ones found together. To see why this is, consider again the Assembly Rules mentioned above. As Belyea and Lancaster are quick to point out, such rules — what they call internal dynamics - are only part of the story. External dynamics, in the form of environmental and dispersal constraints, biogeographical and evolutionary factors, play significant roles (see Figure 3). 
Speciation (evolution) \&

Biogeography (large scale, continental)

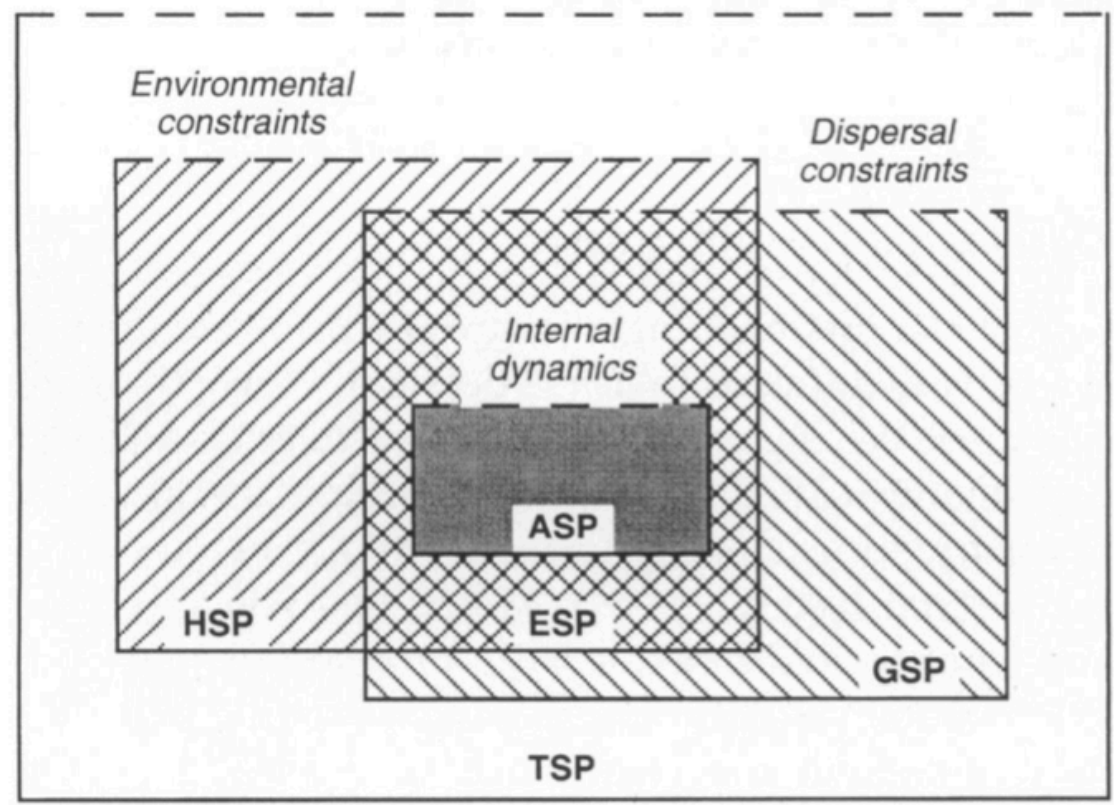

FIGURE 3: Terminology: TSP: total species pool; GSP: geographical species pool; HSP: habitat species pool; ESP: ecological species pool. Both the GSP and HSP are subsets of the TSP, and their intersection set defines the ESP; the ASP is the actual species pool of a community — "the subset of the ESP that results from internal dynamics" (Figure and caption from Belyea and Lancaster 1999, 404).

But these external constraints are highly contingent products of evolution, accidents of dispersal, disruption, priority effects, and so on. So we might explain the fact that two particular species are both represented in a particular type of ecosystem by citing mutualistic relationships (commensalisms, symbioses, and the like) and likewise for further species by the fact that they prey quite specifically on one or both of that pair and conceptualize these relationships in a mechanistic way. But at the same time, we must give due credit to the Gleasonian fact that, in many cases, 
species are brought together by, as it were, common interests. Moreover, these represent only a geographically (indeed, spatiotemporally) limited selection of a much wider pool of species with "similar interests". In a particular environment, we might expect to see organisms make their living in particular ways, but which particular species fulfill those functional roles is an accident of history.

Environments themselves can serve as constraints on the overall structure of ecosystems. We saw earlier the gradient analysis diagram from a slope in the Santa Catalina Mountains (Figure 2) relating vegetation distribution to abiotic factors like moisture and elevation. While the particular taxa might vary from Catalina to Croatia, knowing something about the climate turns out to be very informative when it comes to plant physiognomy and ecology. Mikkelson offers this evocative thought experiment:

Imagine being dropped at a random spot on the land surface of the Earth. Which would allow you to predict the density of plant species around you — that is, the number of species per 10,000 square kilometers — most precisely: knowing the climate, or knowing the landmass on which you stand? Answer: climate wins, hands down. $(2003,1395)$

Other researchers have sought to distill the central climatic factors on ecosystem composition. One of the most well-known, developed by Holdridge (1947, 1967), can be summarized using Figure 4 below: 


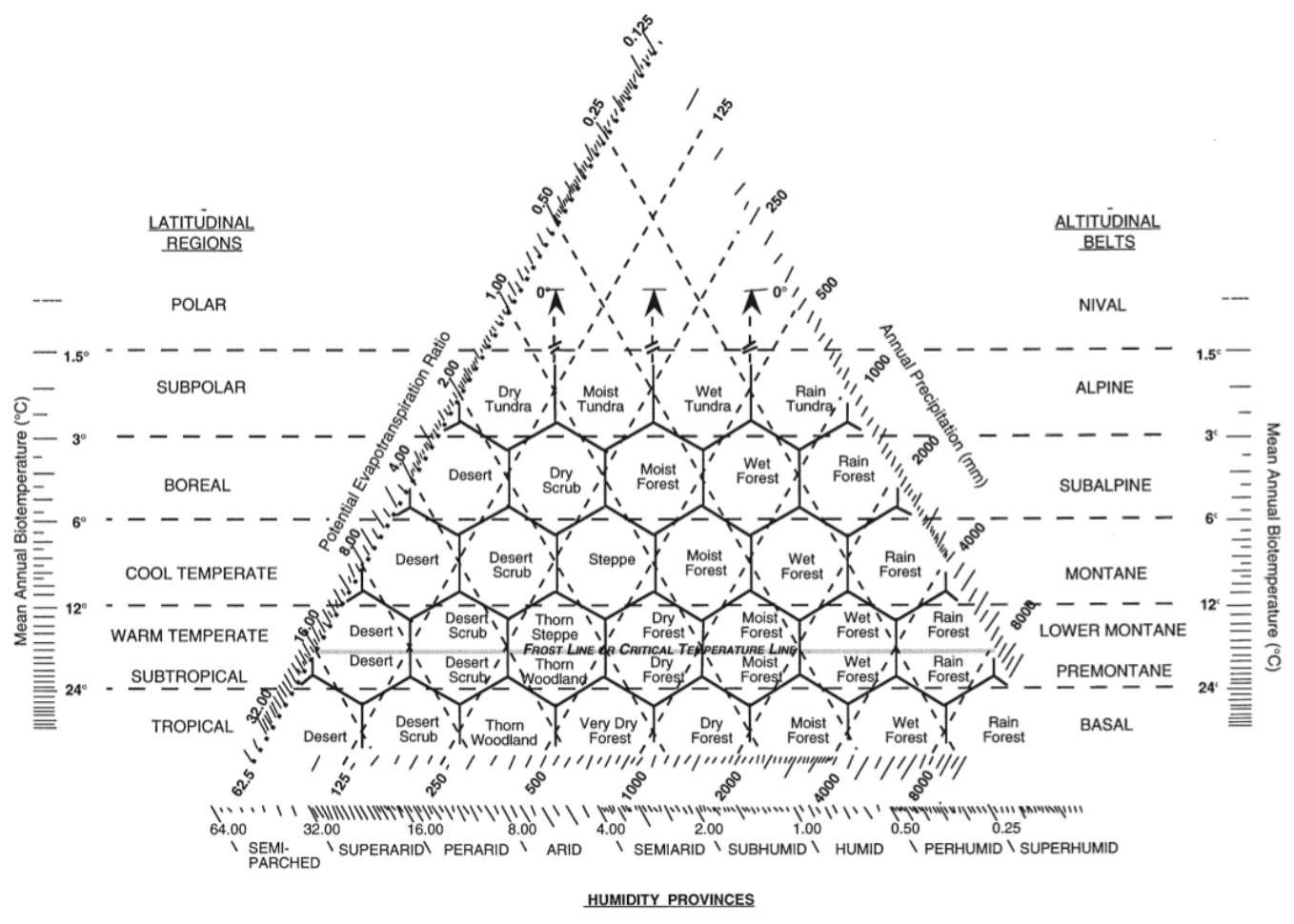

FIGURE 4: Life zones; from Holdridge (1967).

As Lugo et al. put it, "life zones can be subdivided into associations according to site conditions including more detailed climatic data, atmospheric conditions, edaphic conditions [i.e., soil structure/chemistry], topography, and aspect" (1999, 1027).

Biotic factors place further constraints on the sorts of niches available in a particular life-zone. Palik and Engstrom note the role that overstory trees play in forest ecosystems, by, for example, providing resources, altering the "light environments and microclimate", and affecting "the type, number, and abundance of other species" $(1999,71)$. But again these influences only constrain (to different degrees) the range of possible ecological roles that understory biota can take. They do not constitute causal homeostatic mechanisms that explain why these particular properties are stably coinstantiated. For what specific taxa occupy those roles is a product of contingent processes. 


\section{An Alternative}

Let us sum up: while ecosystem types do play some of the familiar epistemic roles of natural kinds, we face two main difficulties in treating them as such. First, the contingency and heterogeneity of ecosystemic types makes them difficult to handle on nomic or essentialist approaches. Despite some enthusiasm for ecological laws, these laws appear to be the wrong sort. Ecosystems are too varied and contingent to be the subjects of nomic generalizations or characterizable by essences. Second, more flexible causal approaches to biological kinds (viz. the HPC account) do not seem especially wellsuited to accommodating the variety of mechanisms (and non-mechanistic factors) that contribute to the epistemic fruitfulness of ecosystemic kinds. We need to either give up on the project or rethink what it is to be a natural kind. And if we take the latter route, we face the challenge of squaring the sense of non-contingency/accidentality attendant to natural kinds in general with the reality of ecosystemic contingency.

Before addressing this issue, though, let us return to the difficulties facing the HPC view's application to ecosystemic kinds. Homeostatic mechanisms are supposed to explain the relative stability/reliability of a cluster of properties — they purport to represent a metaphysical explanation for this stability on a par with essences and laws for stricter accounts. It is this stability that makes such clusters epistemically fruitful. Rather than generalize or jury-rig a conception of mechanism to escape the concerns mentioned above, my suggestion is that we focus not on the metaphysical underpinning — be it an essence or a homeostatic mechanism — that is supposed to ensure a kind of non-contingency or stability of a certain assortment of properties but on characterizing the 
stability that makes natural kinds epistemically useful (see Lipton 1996, 493; Häggqvist 2005, 80 for ideas heading in a similar direction).

What does it mean to attribute "stability" to a cluster of properties? What is it that laws, essences, and causal mechanisms purport to explain in virtue of which kinds play the epistemic roles they typically play? Stability is not (in this context) longevity — not necessarily, anyway. Consider Radon, radioactive bane of basements. The radon-222 isotope has a half-life of about four days on its way to becoming polonium-218. Yet it is as essentialist-friendly an elemental kind as other venerable examples. What is stable about radon-222 is not the existence of any particular sample of it, but rather the pattern of the instantiation of the properties characteristic of (or in this case essential to) the kind. These properties are "systematically sociable" (Chakravartty 2007, 170) both in the sense that they show up together again and again and in the sense that this sociability is modally robust; it still would have been the case had many different circumstances obtained. I call this brand of stability "cliquish stability", distinguishing it from the temporal stability enjoyed by gold and lacking in radioactive isotopes like radon-222. Think of a cluster of properties that comprise a natural kind as a clique of teenagers. They like hanging out together, flitting from store to store at the mall, and so on. They may not stay in any one place very long, but you can bet that if you see a few of them, you'll find the others.

A particular collection of radon-222 atoms lacks temporal stability — unlike, say, some gold atoms that are not radioactive. We cannot rely on them to stick around. But the kind radon-222 does possess cliquish stability in that it is a "modally-robust" fact about the cluster of properties associated with radon-222 that they can be found together. We can rely on these properties to be found together — for a predictably-short time — when instantiated. I argue that it is this second 
sort of reliability, provided by cliquish stability, that is at stake when we are identifying kinds. Elsewhere, I cash out this concept in more formal detail, using some of the apparatus from Marc Lange's approach to natural laws (2015a). What makes laws special, Lange suggests, is their invariance or stability across a broad range of counterfactual suppositions. It would still be the case that $\mathrm{F}=$ ma had many things been different. Specifying the range of this "many" is the technically tricky business. It won't do, for example, to say that they are invariant across all counterfactual suppositions, for among these will be suppositions on which $F \neq m a$. Lange’s central insight is that there is a non-arbitrary way of identifying a certain kind of maximal stability across counterfactual suppositions that identifies the natural laws; the laws are generalizations which are, collectively, as stable as they could have been in the sense that they would still be true on any counterfactual supposition (or suppositions, however nested) logically consistent with the closure of these generalizations (Lange 2000, 2009).

We can adapt this approach to the concept of cliquish stability: a cluster of properties is stable in this sense if their reliable association would still have been the case given any counterfactual scenario consistent with their clustering (and the logical implications of the instantiation of such clusters). Important to notice about Lange's conception of stability is that it makes no reference to any particular metaphysical explanation of stability. Likewise, I propose that a conception of natural kinds as "Stable Property Clusters" (SPC kinds), by foregoing any necessary theoretical ties to causal or nomic concepts, avoids many of the general theoretical problems facing the HPC account as well as the difficulties in application mentioned here. Since cliquish stability is the epistemically important feature of property clusters that gives rise to their epistemic fruitfulness, we need not 
commit ourselves to a particular causal/nomic story of how such stability is obtained. ${ }^{9}$ I hasten to add, however, that the fact that the SPC account makes no explicit reference to causal mechanisms, structures, or "nodes" $\{$ Khalidi, $2013 \# 2235\}$, it is compatible with there being such a mechanistic story. The advantage the SPC account offers is that it can accommodate cases where such stories are difficult to come by or apply, yet the sort of stability that affords a kind's epistemic utility is nevertheless present.

\section{Contingent Anchoring of Natural Kinds}

When we consider the difficulties posed by putative ecosystemic kinds, contingency still looms large. It's clearly false that a given ensemble of properties characterizing a type of ecosystem would still have clustered together had evolution taken a different course, had biogeographical and geological generalizations been otherwise, had happy (and not-so-happy) accidents not come to pass. Is it possible to accommodate the thought that there might be stable clusters of properties associated with particular ecosystemic types even if the conditions that give rise to these clusters are highly contingent? I think that the answer is yes. Though some natural kinds are plausibly "eternal" and universal, e.g., as products of natural laws, I argue that others are defined by clusters of properties cliquishly stable for relevant purposes — which are anchored to a contingent set of conditions, perhaps of a limited spatiotemporal extent. Call such kinds "anchored".

\footnotetext{
${ }^{9}$ For more detail about and defense of these claims, see my (2015a). In that paper, I make the suggestion (omitted here for brevity's sake) that rather than attempting to think of natural kinds as an ontological category to be univocally characterized (as in Lowe 2006; Bird 2007, 2011), we should see "natural kindness" as a sort of status that different categories can enjoy in view of their stability and hence aptness for inference/explanation. This is presumably not a view that Lange would go in for, for as we've seen, Lange takes a particularly strong view of the relationship between laws and natural kinds; kinds must be, in a sense, governed by meta-laws.
} 
To make sense of this phenomenon, we can again draw upon insights of Lange's concerning laws in the special sciences. Recall how Lange made use of the idea of invariance in the face of counterfactual suppositions. Determining the maximum degree of such invariance furnishes a sense of stability appropriate to the strict laws we associate with physics. We can obtain special science laws, on the other hand, by systematically restricting the counterfactual suppositions against which stability is judged (Lange 2004, 2005). We can do this, Lange suggests, by reference to the purposes of the particular field in question:

Since [a] field's concerns may be limited, certain claims and counterfactual suppositions may lie outside of the field's interests. A logically closed set is stable for the purposes of a given science, and hence its members are physical necessities for that field, if and only if all of its members not only are of interest to the field and reliable for the field's purposes, but also would still have been reliable, for the field's purposes, under every counterfactual supposition of interest to the field and consistent with the set. $(2004,101)$

The same basic idea can be applied in the case of cliquish stability. For the purposes of, say, conservation ecology, the fact that evolution might have produced other plant phyla with different physiognomic or functional properties or that biogeographical generalities could easily have been different is of little concern. It does not make the predictions of what one would find in, say, a North American riparian forest any less reliable. Some historical accidents become, as it were, cemented in place. In many cases, these accidents will fall under the heading of "external dynamics": facts about local biotic and abiotic processes, physical environmental constraints, available species pool, functional characteristics of these taxa often represent "frozen accidents" for relevant purposes. 
For investigators working in contexts in which these accidents essentially set the backdrop for their projects - conditions that can neither (easily) be altered nor should be expected to change in the investigatively-relevant future — anchored kinds can serve the same sorts of functions as eternal/universal kinds.

This suggests one way in which the range of counterfactuals against which stability is understood becomes settled: such background conditions that are beyond our intervention do not represent very tractable "what-if" questions. Had woody plans never evolved, what would ecosystems have been like? Ecology has little interest in such far-out counterfactuals (nor much ability to evaluate them). So ecology rightly contracts the range of relevant counterfactuals on which stability is judged. Certain projects in ecology might also fix on a particular spatiotemporal range of application or generality at which properties are described. These restrictions interact in obvious ways. For example, if we are talking about Amazonian riparian forests, we might confidently characterize them as being frequented by hippopotamuses and warthogs which in turn contribute to the habitat structure for other organisms (Brinson and Verhoeven 1999, 267). But if we wished to speak more generally about riparian forests in other spatiotemporal contexts — say, in the Mississippi basin — references to specific taxa may be inappropriate and unworkable. Indeed, it might turn out that despite certain family resemblances, there is simply no such thing as a riparian forest at a global scale, but that at smaller, continental scales, there is. Alternatively, as a domain widens, we might see a change in how such kinds are characterized, moving to fewer more general functional properties and taxa of higher ranks or more general ecosystemic role (e.g., scavenger or woody grass). Domain-restriction and relativization in a sense enables anchored kinds' successful employment. 
Note in the above how the purposes of the relevant projects are not purely conventional matters. They are, at least in part, reflections of ecologists' recognition of the limits of what they can project and the extent of what they may presume when it comes to background conditions and external dynamics. Admittedly, however, a degree of conventionalism may linger when it comes to the sorts of properties (functional versus structural or taxon-specific, levels of granularity, and so on) ecologists opt to focus on when categorizing the ecological world. But having settled on such matters, the SPC kinds account retains a realist flavor to the extent that there are facts about whether, so restricted and identified, the clusters are stable.

It seems to me that the SPC account and the recognition and acceptance of contingent anchoring fits well with the ways ecologists describe their practice. While there is still some controversy among ecologists about how to best deal with these issues, we do see quite a bit of acceptance and comfort with the idea that ecological knowledge accrues within particular domains. In replying to an article critical of the continued prospects of community ecology (Lawton 1999), Daniel Simberloff noted in his Presidential Address to the American Society of Naturalists that "Laws and models in community ecology are highly contingent, and their domain is usually local. This fact does not mean that community ecology is a weak science; in fact, it is the locus of exciting advances, with growing mechanistic understanding of causes, patterns, and processes....[and] is crucial in understanding and responding to many environmental problems, including those posed by global changes" (2004, 787).

One might wonder whether Simberloffs characterization of the work of community ecology is not in some tension with my non-causal — or better, "causal-agnostic" — approach to SPC kinds. But while I believe that the concept of a natural kinds need not involve causal factors (and runs into 
trouble when it insists on some kind of "causal glue" in all cases), I certainly would not want to suggest that the investigation of causal mechanisms is not productive and won't often fill out our understanding of particular systems or local kinds. Walter Dodds points out that natural historians are able to synthesize their general knowledge of ecosystems with their "correlative knowledge of local contingencies":

If you have ever spent time in the field with a good natural historian, it is clear they understand a lot about how their ecological system of interest works. A good natural historian knows where and when plants and animals can be found, who eats what, and how climate influences organisms. Several factors such as flowering time, emergence from hibernation, arrival of migratory birds, and sequence of autumn leaf fall can be predicted within days to weeks. $(2009,155)$

Different ecological norms and projects, tutored by what the world affords us, influence what level of generality and precision we should demand from an ecosystemic kind. But even if the status of being a natural kind of ecosystem is determined primarily by the stability of the system, much productive ecological work is rightly devoted to uncovering specific ways in which that stability is achieved in a particular case (or perhaps in a particular region). Stability within even a specific natural kind may be multiply realized.

Discussion of the phenomenon of "Coordinated Stasis" (Brett et al. 1996; 2012) also makes clear that the mechanisms produce stability - either temporal or cliquish — may be unknown and expected to vary across examples. Brett and colleagues originally hypothesized this phenomenon in light of field observations from biofacies from the Silurian-Devonian interval found in the northern Appalachian Basin region $(2012,24)$. The fossil record revealed long periods during which many 
species were found together and which ceased together, "apparently terminated by a geologically abrupt interval of at least local extinction;" these "ecological-evolutionary" (EE) subunits were defined as "blocks of coordinated stasis" (25). As Ivany et al. put it:

The pattern of "coordinated stasis" suggests that faunas persist in their preferred environments for intervals of up to several million years with little net change in assemblage composition or morphology of component taxa (taxonomic stasis), and that faunal associations tend to remain relatively consistent in terms of ecological properties such as guild structure (ecological stasis). (2009, 499)

Fascinating in its own right, this phenomenon lends indirect support to the SPC approach to kinds in its ambivalence over particular mechanisms. Brett notes that early criticism conflated the pattern of coordinated stasis with one of its possible explanations, "ecological locking" (Morris et al. 1995): "The concept of coordinated stasis deals with patterns in the fossil record and, although it may have important implications for ecological-evolutionary processes, it was never intended to present hypotheses about the causes of these patterns" $(2012,27)$.

The EE subunits studied by Brett and company may not be the most representative examples of ecosystemic types - associations lasting long enough (millions of years) to show up clearly in the fossil record are probably the exception rather than the rule — but they illustrate that sometimes what matters most when it comes to identifying and re-identifying kinds of ecosystems is the highlevel pattern of coinstantiation. To the extent that such patterns are stable enough to serve the needs of ecological and conservation-management inquiry (if relative to certain spatiotemporal contexts), different types of ecosystems can be reckoned among the natural kinds. 


\section{ACKNOWLEDGEMENTS}

Thanks to audiences at the IHPST workshop on "Causation and Metaphysics" organized by Andrew McFarland (particularly Andrew, P.D. Magnus, Thomas Reydon) and at POBAM2014 (particularly Matt Barker, Matt Haber, Roberta Millstein, Elliott Sober, and Joel Velasco) for helpful suggestions. Thanks also to two anonymous referees for Synthese for constructive criticism and Jay Odenbaugh and Jeff Trop for sound advice on earlier drafts.

\section{REFERENCES}

Beatty, John (1995) "The Evolutionary Contingency Thesis," in G. Wolters and J. G. Lennox (eds.), Concepts, Theories, and Rationality in the Biological Sciences. Pittsburgh: University of Pittsburgh Press, $45-81$.

Begon, Michael, Colin R.. Townsend, and John L. Harper (2006) Ecology: From Individuals to Ecosystems. 4th ed. Malden, MA: Blackwell Publishing.

Belyea, Lisa R., and Jill Lancaster (1999) "Assembly Rules Within a Contingent Ecology," Oikos 86:402-416.

Bird, Alexander (2007) Nature's Metaphysics: Laws and Properties. Oxford: Oxford University Press.

Bird, Alexander (2011) "Are Any Kinds Ontologically Fundamental?," in Tuomas Tahko (ed.), Contemporary Aristotelian Metaphysics. Cambridge: Cambridge University Press.

Boyd, Richard (1991) "Realism, Anti-Foundationalism and the Enthusiasm for Natural Kinds," Philosophical Studies 61:127-148.

Boyd, Richard (1999) "Homeostasis, Species, and Higher Taxa," in Robert A. Wilson (ed.), Species: New Interdisciplinary Essays. Cambridge: MIT Press.

Brett, Carlton E (2012) "Coordinated Stasis Reconsidered: A Perspective at Fifteen Years," in John A Talent (ed.). Dordrecht: Springer Netherlands, 23-36.

Brett, Carlton E, Linda C Ivany, and Kenneth M Schopf (1996) "Coordinated stasis: an overview," Palaeogeography 127:1-20.

Brinson, Mark M., and Jos Verhoeven (1999) "Riparian Forests," in Malcolm L. Hunter (ed.), Maintaining Biodiversity in Forest Ecosystems. Cambridge: Cambridge University Press.

Bryant, Rachel (2012) "What If Ecological Communities Are Not Wholes?," in William P. Kabasenche, Michael O'Rourke and Matthew H. Slater (eds.), The Environment: Philosophy, Science, and Ethics Cambridge, MA: The MIT Press.

Budiansky, S. (1995) Nature's Keepers: The New Science of Nature Management. New York: Free Press. Chakravartty, Anjan (2007) A Metaphysics for Scientific Realism. Cambridge: Cambridge University Press.

Clements, Frederic (1916) Plant Succession: An Analysis of the Development of Vegetation. Publication no. 242. Washington, D.C.: Carnegie Institution of Washington.

Cody, Martin, and Jared Diamond (1975) Ecology and Evolution of Communities. Cambridge: Belknap Press.

Cooper, Gregory J. (2003) The Science of the Struggle for Existence: On the Foundations of Ecology. Cambridge: Cambridge Unviersity Press.

Craver, Carl F. (2009) "Mechanisms and Natural Kinds," Philosophical Psychology 22 (5):575-594.

Craver, Carl F. (2013) In Search of Mechanisms: Discoveries across the Life Sciences. Chicago: University of Chicago Press.

Devitt, Michael (2008) "Resurrecting Biological Essentialism," Philosophy of Science 75 (3):344-382.

Dodds, Walter K. (2009) Laws, Theories, and Patterns in Ecology. Berkeley: University of California Press. Dupré, John (1993) The Disorder of Things. Cambridge: Harvard University Press.

Ellis, Brian (2001) Scientific Essentialism. Cambridge: Cambridge University Press.

Ginzburg, Lev, and Mark Colyvan (2004) Ecological Orbits: How Planets Move and Populations Grow. New York: Oxford University Press. 
Gleason, Henry A. (1917) "The Structure and Development of the Plant Association," Bulletin of the Torrey Botanical Club 53:463-481.

Gleason, Henry A. (1926) "The Individualistic Concept of the Plant Association," Bulletin of the Torrey Botanical Club 53:7-26.

Gleason, Henry A. (1939) "The Individualistic Concept of the Plant Association," American Midland Naturalist 21:92-110.

Golley, Frank Benjamin (1993) A History of the Ecosystem Concept in Ecology: More Than the Sum of the Parts. New Haven: Yale University Press.

Gould, Stephen Jay (1989) Wonderful Life. New York: W. W. Norton \& Company.

Griffiths, Paul E. (1997) What Emotions Really Are: The Problem of Psychological Categories. Chicago: University of Chicago Press.

Griffiths, Paul E. (1999) "Squaring the Circle: Natural Kinds with Historical Essences," in Robert A. Wilson (ed.), Species: New Interdisciplinary Essays. Cambridge: MIT Press.

Häggqvist, Sören (2005) "Kinds, Projectibility and Explanation," Croatian Journal of Philosophy 5 (13):7187.

Haufe, Chris (2013) "From Necessary Chances to Biological Laws," British Journal for the Philosophy of Science 64:279-295.

Hempel, Carl G. (1965) "Fundamentals of Taxonomy", reprinted in his Aspects of Scientific Explanation, pp. 137-154. New York: The Free Press.

Holdridge, L.R. (1947) "Determination of World Plant Formations from Simple Climatic Data," Science 105:367-368.

Holdridge, L.R. (1967) Life Zone Ecology. San Jose, Costa Rica: Tropical Science Center.

Ivany, Linda C, Carlton E Brett, Heather L B Wall, Patrick D Wall, and John C Handley (2009) "Relative taxonomic and ecologic stability in Devonian marine faunas of New York State: a test of coordinated stasis," Paleobiology 35 (4):499-524.

Khalidi, Muhammad Ali (2013) Natural Categories and Human Kinds. Cambridge: Cambridge University Press.

Kitcher, Philip (1984) "Species," Philosophy of Science 51:308-333.

Kornblith, Hilary (1993) Inductive Inference and its Natural Ground. Cambridge: MIT Press.

Lange, Marc (1995) "Are There Natural Laws Concerning Particular Biological Species," Journal of Philosophy $92(8): 430-451$.

Lange, Marc (2000) Natural Laws in Scientific Practice. New York: Oxford University Press.

Lange, Marc (2004) "The Autonomy of Functional Biology: a Reply to Rosenberg," Biology and Philosophy 19:93-109.

Lange, Marc (2005) "Ecological Laws: What Would They Be and Why Would They Matter?," Oikos 110 (2):394-403.

Lange, Marc (2009) Laws and Lawmakers. Oxford: Oxford University Press.

Lawton, John H. (1999) "Are There General Laws in Ecology," Oikos 84:177-192.

Lipton, Peter (1996) "Review of Kornblith, Inductive Inference and its Natural Ground," Philosophy and Phenomenological Research 56 (2):492-494.

Lowe, E. J. (2006) The Four-Category Ontology: A Metaphysical Foundation for Natural Science. Oxford: Oxford University Press.

Lugo, A.E., S.L. Brown, R. Dodson, T. S. Smith, and H. H. Shugart (1999) "The Holdridge Life Zones of the Conterminous United States in Relation to Ecosystem Mapping," Journal of Biogeography 26:10251038.

MacArthur, R.H., and E.O. Wilson (1967) The Theory of Island Biogeography. Princeton: Princeton University Press.

Magnus, P.D. (2012) Scientific Enquiry and Natural Kinds: From Planets to Mallards. London: PalgraveMacmillan. 
Mikkelson, Gregory M. (2003) "Ecological Kinds and Ecological Laws," Philosophy of Science 70:1390-1400.

Mitchell, Sandra (2000) "Dimensions of Scientific Law," Philosophy of Science 67:242-265.

Mitchell, Sandra (2002) "Contingent Generalizations: Lessons from Biology," in Renate Mayntz (ed.), Akteure - Mechanismen - Modelle. Frankfurt: Campus Verlag.

Morin, Peter J. (2011) Community Ecology. 2nd ed. Oxford: Wiley-Blackwell.

Morris, P. J., L. C. Ivany, and K. M. Schopf (1995) "The Challenge of Paleoecological Stasis: Reassessing Sources of Evolutionary Stability," Proceedings of the National Academy of Science 92:11269-11273.

Mumford, Stephen (2005) "Kinds, Essences, Powers," Ratio 18 (4):420-436.

Nagel, Ernest (1961) The Structure of Science: Problems in the Logic of Scientific Explanation. New York: Harcort, Brace, and World.

Odenbaugh, Jay (2007) "Seeing the Forest and the Trees: Realism about Communities and Ecosystems," Philosophy of Science 74:628-641.

Odum, Eugene P. (1953) Fundamentals of Ecology. Philadelphia: W.B. Saunders.

Okasha, Samir (2002) "Darwinian Metaphysics: Species and the Question of Essentialism," Synthese 131:191-213.

Palik, Brian, and R. Todd Engstrom (1999) "Species Composition," in Malcolm L. Hunter (ed.), Maintaining Biodiversity in Forest Ecosystems. Cambridge: Cambridge University Press.

Putnam, Hilary (1975) "Is Semantics Possible?", reprinted in his Mind, Language and Reality: Philosophical Papers, Vol. 2. Cambridge: Cambridge University Press.

Rosenberg, Alex (2001) "How is Biological Explanation Possible?," British Journal for the Philosophy of Science 52:735-760.

Simberloff, Daniel S. (1974) "Equilibrium Theory of Island Biogeography and Ecology," Annual Review of Ecology and Systematics 5:161-182.

Simberloff, Daniel S. (2004) "Community Ecology: Is It Time to Move On?," The American Naturalist 163 (6):787-799.

Slater, Matthew H. (2013a) Are Species Real? London: Palgrave-Macmillan.

Slater, Matthew H. (2013b) "Review of Scientific Enquiry and Natural Kinds," Notre Dame Philosophical Reviews. URL $=<$ http://ndpr.nd.edu/news/40779-scientific-enquiry-and-natural-kinds-from-planets-tomallards/>.

Slater, Matthew H. (2015a) "Natural Kindness," The British Journal for the Philosophy of Science 66 (2):375411.

Slater, Matthew H. (2015b) "Review of Natural Categories and Human Kinds," British Journal for the Philosophy of Science 66:1017-1023.

Sober, Elliott (1980) "Evolution, Population Thinking, and Essentialism," Philosophy of Science 47:350-383.

Sober, Elliott (1997) "Two Outbreaks of Lawlessness in Recent Philosophy of Biology," Philosophy of Science 64:S458-467.

Tansley, A.G. (1935) "The Use and Abuse of Vegetational Terms and Concepts," Ecology 16:284-307.

Whittaker, R.H., and W.A. Niering (1965) "Vegetation of the Santa Catalina Mountains, Arizona: A Gradient Analysis of the South Slope," Ecology 46:429-452.

Wieder, R.K., and D.H. Vitt, eds. (2006) Boreal Peatland Ecosystems. Berlin: Springer-Verlag.

Wilson, Robert A. (1999) "Realism, Essence, and Kind: Resuscitating Species Essentialism?," in Robert A. Wilson (ed.), Species: New Interdisciplinary Essays. Cambridge: MIT Press.

Wilson, Robert A. (2005) Genes and the Agents of Life. Cambridge: Cambridge University Press.

Wilson, Robert A., Matthew J. Barker, and Ingo Brigandt (2007) "When Traditional Essentialism Fails: Biological Natural Kinds," Philosophical Topics 35 (1/2):189-215.

Woodward, Jim (2001) "Law and Explanation in Biology: Invariance is the Kind of Stability That Matters," Philosophy of Science 68:1-20.

Zimmerman, E., T. Davis, G. Podniesinski, M. Furedi, J. McPherson, S. Seymour, B. Eichelberger, N. Dewar, J. Wagner, and J. Fike, eds. (2012) Terrestrial and Palustrine Plant Communities of Pennsylvania. 
2nd ed. Harrisburg, PA: Pennsylvania Natural Heritage Program, Pennsylvania Department of Conservation and Natural Resources. 